\title{
NARRATIVA COMO ACONTECIMENTO NO FILME CENTRAL DO BRASIL
}

\author{
Narrative as event in the film Central Station
}

Narrativa como acontecimiento en la película Central do Brasil

Cyntia Gomes Calhado

Crítica, pesquisadora e professora em cursos de Comunicação e Audiovisual no FIAMFAAM - Centro Universitário. É doutoranda do Programa de Estudos Pós-Graduados em Comunicação e Semiótica da Pontifícia Universidade Católica de São Paulo (PUC-SP). cyntia.calhado@gmail.com

\begin{abstract}
Resumo
O objetivo deste artigo é realizar uma leitura da narrativa audiovisual a partir do conceito de acontecimento, buscando oferecer nova visada para além de seus aspectos representacionais tradicionalmente enfocados. Utilizaremos como objeto da análise a cena da romaria do longametragem Central do Brasil (1998) de Walter Salles, filme que tem sido pensado primordialmente no campo representacional. Como instrumental teórico, adotaremos o texto "As virtualidades da narrativa cinematográfica" (2013), em que André Parente apresenta uma crítica interna ao sistema-cinema de Gilles Deleuze. Pretendemos demonstrar que a narrativa como acontecimento intensifica a experiência cinematográfica, pois o tempo da imagem e o do espectador se identificam.
\end{abstract}

Palavras-chave: Acontecimento. Narrativa audiovisual. Central do Brasil.

\begin{abstract}
The objective of this article is to interpretate the audiovisual narrative from the concept of event, seeking to provide a new approach besides its representative aspects traditionally focused. The object of study is the pilgrimage scene from Walter Salles's feature film Central Station (1998), that has being thought mainly in it's representational field. As theoretical tools, we will adopt the text "The virtualities of the cinematographic narrative" (2013), in which André Parente presents an internal criticism to Gilles Deleuze's system-cinema. We aim to demonstrate that the narrative as event intensifies the cinematographic experience, because the time of the image and the one from de spectator identifies.
\end{abstract}

Key words: Event. Audiovisual Narrative. Central Station.

\section{Resumen}

El objetivo de este artículo es realizar una lectura de la narrativa audiovisual a partir del concepto de acontecimiento, buscando ofrecer nuevo enfoque además sus aspectos 
representacionales tradicionalmente analizados. Utilizaremos como objeto de análisis la scena de la romería del largo metrage Central do Brasil (1998) de Walter Salles, película que ha sido pensada primordialmente en el campo representacional. Como instrumental teórico, adoptaremos el texto "Las virtualidades de la narrativa cinematográfica" (2013), en que André Parente presenta una crítica interna al sistema-cine de Gilles Deleuze. Pretendemos demostrar que la narrativa como acontecimiento intensifica la experiencia cinematográfica, porque el tiempo de la imagen y el de lo espectador se identifican.

Palabras clave: Acontecimiento. Narrativa audiovisual. Central do Brasil.

\section{INTRODUÇÃO}

No texto "As virtualidades da narrativa cinematográfica" (2013), André Parente apresenta uma crítica interna ao sistema-cinema criado pelo teórico francês Gilles Deleuze, especificamente as relações entre o virtual e a narrativa, instância entendida por Deleuze como condicionada à imagem. Parente defende que não existe oposição entre imagem e narrativa, mas entre concepções diferentes destes dois conceitos: uma afirma que ambos são sistemas de representação e outra que são acontecimentos. Ele busca mostrar que a narrativa também é acontecimento e não apenas representação.

O objetivo do presente artigo é analisar a cena da romaria do longa-metragem Central do Brasil (1998) de Walter Salles a partir do conceito de acontecimento de Parente. Para além de seus aspectos representacionais tradicionalmente estudados, pretendemos demonstrar que a narrativa do filme também se configura como acontecimento em planos dotados de maior plasticidade. Para tanto, apresentaremos a conceituação de Parente a respeito da narrativa audiovisual como acontecimento e, em seguida, realizaremos análise fílmica da cena selecionada a fim de identificar este aspecto.

\section{NARRATIVA AUDIOVISUAL COMO ACONTECIMENTO}

Segundo a tipologia deleuziana, os cinco processos imagéticos responsáveis pela formação das imagens cinematográficas são, por um lado, a especificação, a diferenciação e a integração das imagens-movimento e, por outro, a ordenação e a seriação das imagens-tempo. A imagem-movimento é aquela relacionada ao esquema sensório-motor, que especifica-se em imagem-percepção (o que se vê), imagem-afecção (o que se sente), imagem-ação (o que se faz) etc. A imagem-movimento se encadeia conforme o esquema sensório-motor e, ao fazê-lo, 
integra-se em um todo, mas está constantemente se diferenciando em objetos, atos e formas de realidade. Normalmente identificada ao cinema clássico, a imagem-movimento estabelece relações do homem com o mundo, que vão variar segundo a forma como cada cineasta as conceber.

Ao processo de especificação das imagens, Parente acrescenta que ele se produz somente quando existe uma história, que "se manifesta em um campo de tensões e forças, conforme a distribuição de objetos, obstáculos, meios e desvios que afetam as relações sujeito/objeto" (2013, p. 263). Para o autor, os processos imagéticos da imagem-movimento estabelecidos por Deleuze correspondem aos processos de toda narrativa verídica, sendo esta imagética ou não.

Já a imagem-tempo, condicionada por processos narrativos de temporalização e relacionada à narrativa não verídica, se distingue pela qualidade intrínseca daquilo que vem a ser na imagem (seriação) e pela coexistência de relações de tempo na imagem (ordenação).

A série (qualidade) e a ordem (coexistência) do tempo rompem com o tempo cronológico, linear, e promovem outros modos de narração e de narrativa no cinema. $\mathrm{Se}$, na narrativa verídica, composta de imagens-movimento, tudo remete a um, na narrativa falsificante da imagem-tempo, existe uma multiplicidade irredutível que afeta o cinema (ibid., p. 267).

Marie-Claire Ropars-Wuillemier foi a teórica que chamou atenção para o fato de que o cinema do pós-guerra tinha se transformado de "arte do movimento" para arte do tempo. Para ela, o tempo estava se tornando o personagem principal do cinema e, deste modo, ele se constituiria como uma "escritura", tendo em vista que era necessário "ler" a imagem.

\footnotetext{
Aos olhos do espectador, o tempo é percebido como vivido, à medida que a representação deixa de ser o suporte de uma ação imediatamente interpretável: aparecem então as diversas maneiras próprias ao tempo de passar sobre os seres, conforme as diversas maneiras próprias aos seres de passar no tempo (ROPARSWUILLEUMIER, 1970, p. 132 apud PARENTE, 2013, p. 269)
}

De acordo com a autora, no cinema moderno, muda-se de uma estética dramática a uma estética narrativa, de uma estética da representação a uma estética da escritura, de uma sucessão a uma duração, de uma história a uma narrativa.

Diferentemente de Deleuze, Parente acredita que os processos de temporalização são, ao mesmo tempo, imagéticos e narrativos. O que quer dizer que as imagens-tempo não são primeiras em relação às operações de temporalização narrativas, mas é a narração temporalizante que condiciona tanto as imagens-tempo quanto a narrativa não verídica. 
Mesmo que a imagem-tempo suponha homens, situações, histórias, ações, ela supera as relações sensório-motoras que eles mantêm.

\begin{abstract}
Não há meio de fundar o tempo da imagem, que não se confunde com o presente abstrato do que é "representado" na imagem (objetos, ações, formas de realidade e suas relações sensório-motoras), se introduzirmos nela uma fissura, por meio da qual a narração se desdobra e se torna contemporânea da ação que descreve. A imagem deve se duplicar ou se abrir em um movimento infinito que a faça sair da consciência daquele que a percebe ou que age. Essa operação supõe uma conduta particular de memória, de narração, que se pode denominar, de acordo com Pierre Janet, de "presentificação" (ibid., p. 268).
\end{abstract}

Desta forma, o ato narrativo de presentificação é de outra natureza e não se confunde com a narração ou com a narrativa de uma ação presente ou passada. A narrativa não verídica não representa ou comunica um acontecimento, mas restitui o efeito vivo dos fatos e das falas, restitui suas presenças. Desta forma, o ato de presentificação introduz uma fissura ou um desdobramento nas imagens, nos enunciados, nas ações, nos personagens, nos narradores e nas narrativas produzidas, afetando as imagens, sons e suas relações no cinema moderno. Para Parente, a narrativa como acontecimento só pode existir no cinema quando se produz um desdobramento no filme por meio do qual a imagem exprime e afirma o tempo.

\title{
2.1 Análise da cena da romaria de Central do Brasil
}

Podemos verificar o estatuto da narrativa como acontecimento no filme Central do Brasil. Na produção, uma narrativa não-verídica apresenta a história de Dora, professora aposentada cujo trabalho é escrever cartas para analfabetos na estação que intitula o longa, no Rio de Janeiro. Ela resolve acompanhar o garoto Josué em uma viagem para Bom Jesus do Norte, Pernambuco, em busca do pai, depois que a mãe do menino morre atropelada nos arredores da estação. $\mathrm{O}$ argumento do filme tem diversos pontos de contato com o roteiro de Alice nas Cidades (Wim Wenders, 1974).

Apesar de Central permanecer, em grande medida, no registro da imagem-movimento (ou transparência), podemos notar fissuras em sua narrativa, momentos em que o tempo se constitui como escritura e, então, instaura-se a opacidade narrativa. Conceitos de Ismail Xavier (2005), transparência se refere à operação cinematográfica em que o dispositivo é ocultado em favor de um ganho maior de ilusionismo, já a situação de opacidade seria quando o dispositivo é revelado, gerando maior distanciamento e crítica. 
Em diversas passagens do filme observamos momentos de opacidade, mas uma delas é particularmente interessante, pois coincide com o ponto de virada da narrativa. Trata-se da cena da romaria no Nordeste que tecnicamente é marcada pelo virtuosismo de sua fotografia, conhecida pelo fato de grande parte da fonte de iluminação ser proveniente de velas.

Caracterizada como uma personagem cínica, Dora aos poucos vai revelando sua bondade como consequência de sua aproximação de Josué. Este arco dramático de ressensibilização tem como ápice o transe religioso da personagem em meio a fogos de artifício, velas e ladainhas da romaria, que culmina no desmaio de Dora na Casa dos Milagres, espécie de templo em que religiosos acendem velas e deixam imagens de familiares aos santos. O termo ressensibilização é utilizado pelo diretor (em entrevista a BENTES; MATTOS; AVELLAR, 1998, p. 17.) para explicar esta mudança na trajetória da personagem. Interessante observar sua escolha lexical, já que o termo sensibilização também é empregado em referência ao processo de formação de imagens na película fotográfica. Veremos, em seguida, que este aspecto da materialidade do cinema está presente na cena como um índice metalinguístico.

Lúcia Nagib (2006, p. 74) identifica esta sequência como uma citação de Glauber Rocha às avessas. Se nos filmes do cinemanovista, o transe religioso assumia o sentido de crítica à alienação, no longa de Salles produz o "milagre da revelação". A opção lexical de Nagib pela palavra revelação a respeito do cinema de Walter Salles tampouco nos parece casual. Já que a poética do cineasta inclui a visão do cinema como revelação - um pensamento defendido pelo teórico francês André Bazin, que associava o realismo cinematográfico à noção espiritual de "revelação", fruto da concepção de uma ligação ontológica entre a película e o objeto representado. "O cinema torna-se um sacramento; um altar onde uma espécie de transubstanciação toma lugar” (STAM, 2010, p. 95). A abordagem de Bazin vai na direção do conceito de arte defendido por Walter Benjamin em seu famoso texto "A Obra de Arte na Era de sua Reprodutibilidade Técnica", publicado em 1935. O autor observa que atribui-se à arte um valor de culto e, desta forma, ela ocupa o lugar de uma prática ritualística nas sociedades secularizadas.

Após esta breve contextualização, realizaremos análise fílmica desse trecho do longa com o objetivo de identificar nele o procedimento da imagem-tempo e o ato narrativo de presentificação. A cena inicia-se no registro da imagem-movimento: a personagem corre atrás de Josué que se perdeu na multidão de romeiros e acaba entrando na Casa dos Milagres. A 


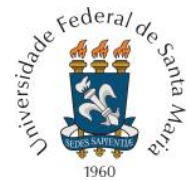

luz e a imagem são o leitmotiv (motivo condutor) dessa cena, como podemos ver nos frames abaixo.

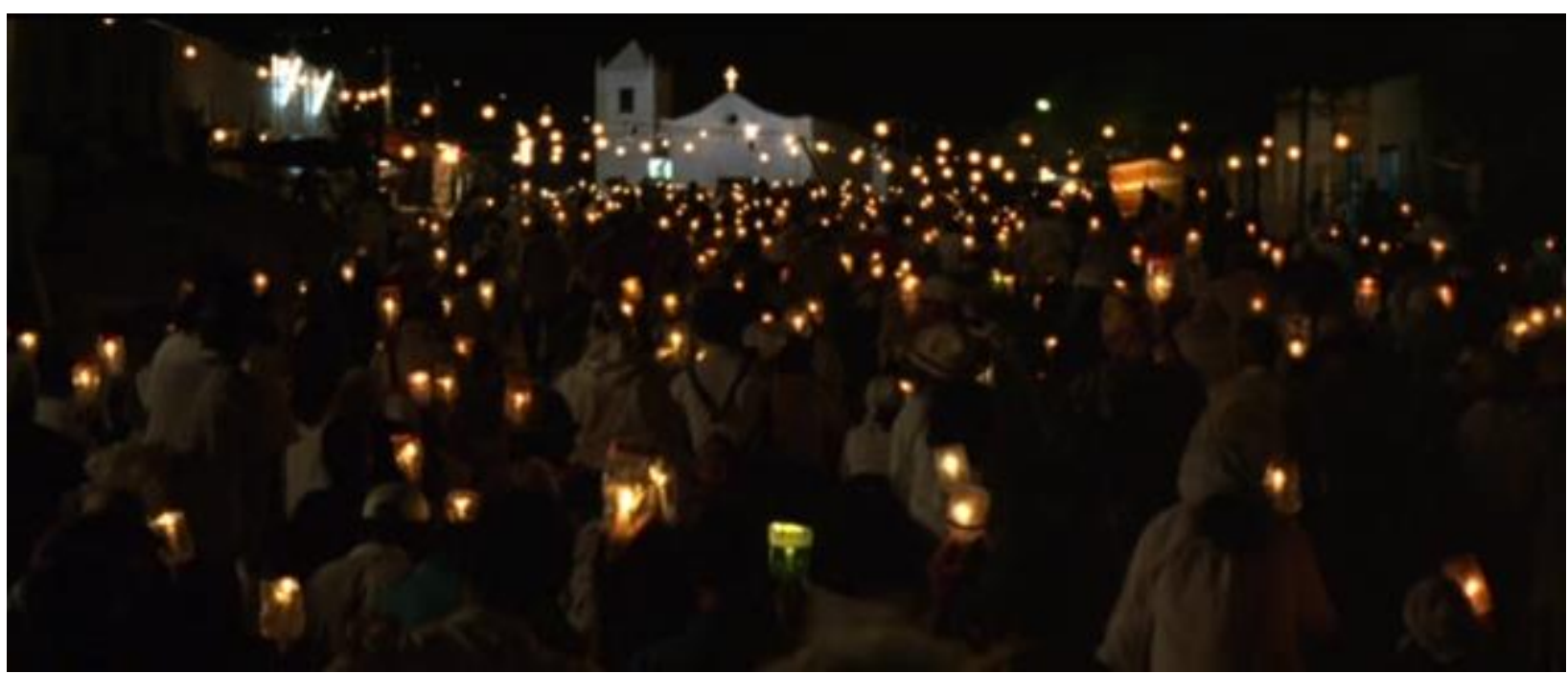

Figura 1 - No início da cena, nota-se a ênfase nos pontos de luz das velas dos romeiros, e o templo ao fundo ${ }^{1}$

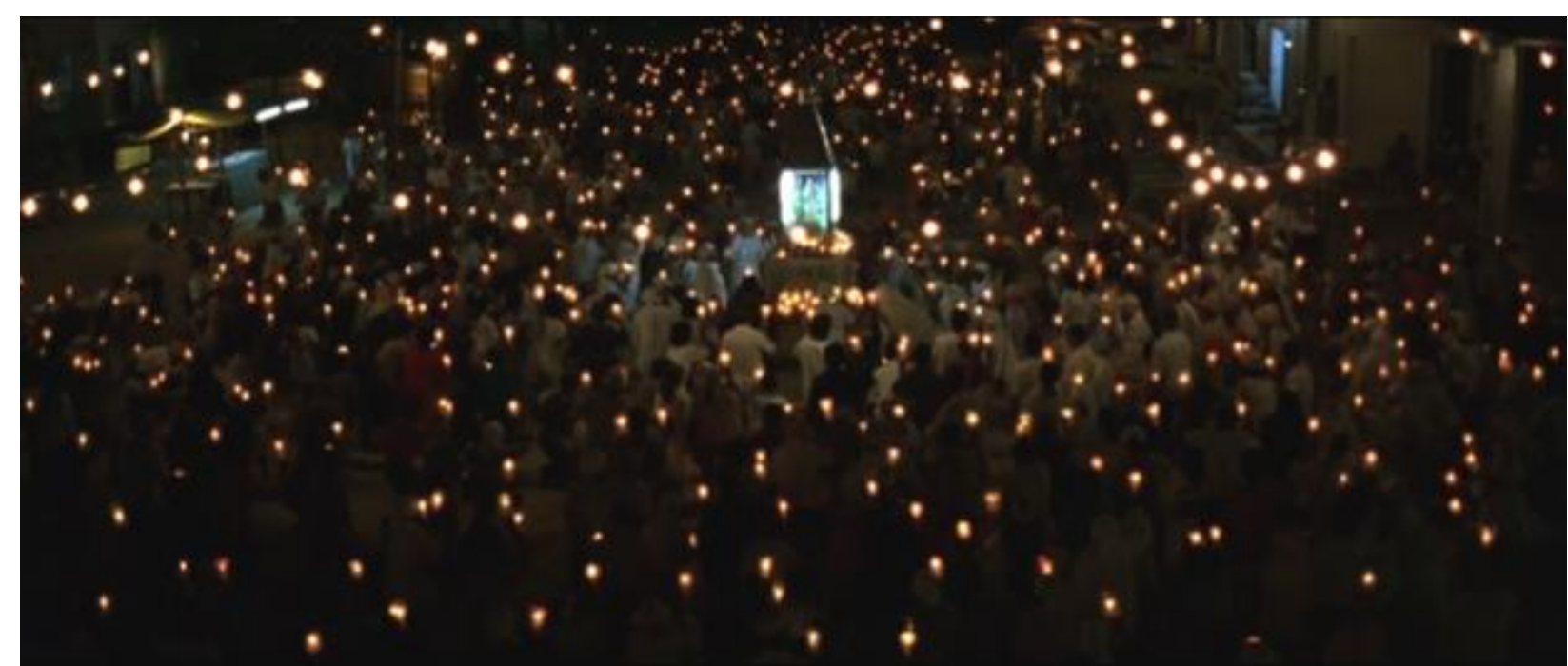

Figura 2 - Bem iluminada, a imagem da Virgem Maria com o menino Jesus ocupa o centro do plano

\footnotetext{
${ }^{1}$ Todas as figuras são frames do filme Central do Brasil.
} 


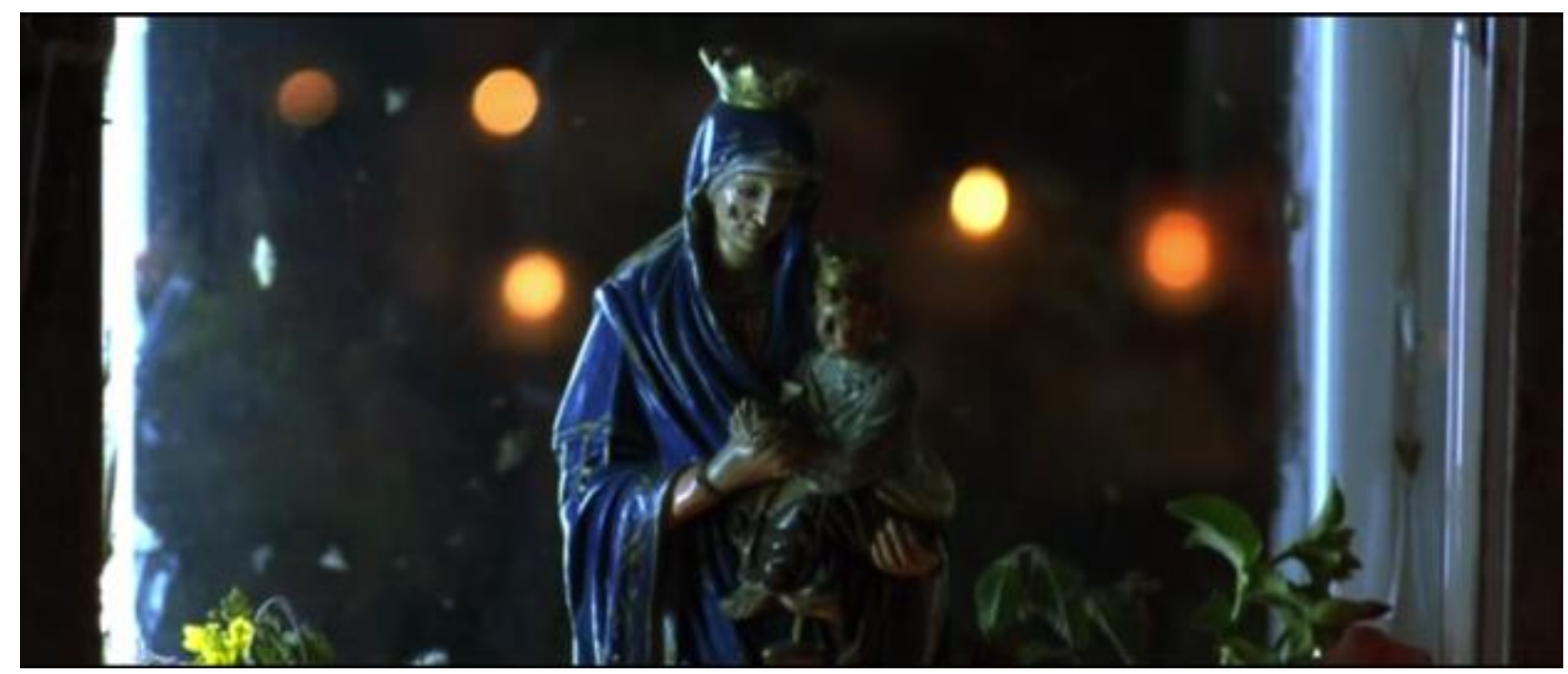

Figura 3 - Plano aproximado da imagem da Virgem Maria com o menino Jesus e pontos de luz ao fundo

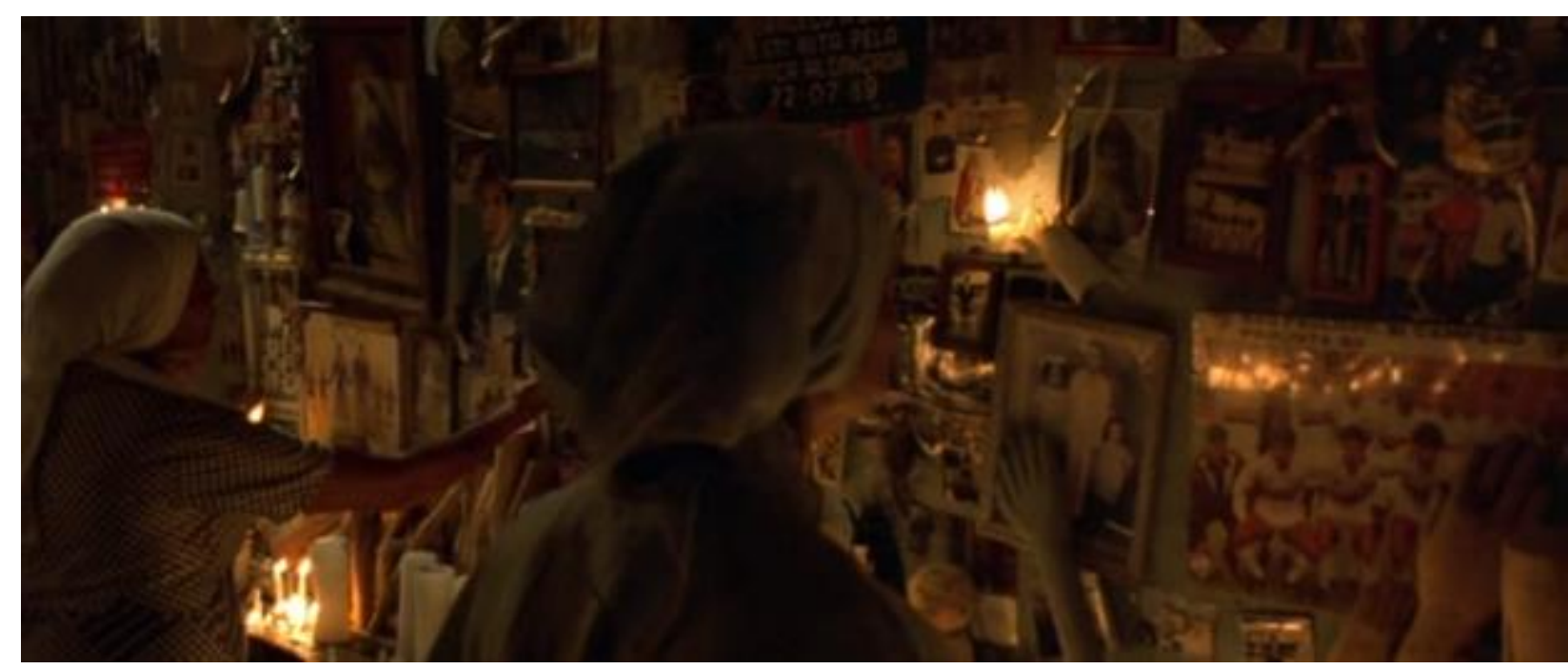

Figura 4 - Dentro da Casa dos Milagres, inúmeras fotografias tornam-se visíveis pela iluminação de velas

Um aspecto importante desse trecho do filme, como mencionamos, é seu caráter metalinguístico. Nagib considera que o foco à materialidade da imagem, conferida pelas fotografias em Central do Brasil, seria uma herança de Wim Wenders:

A fotografia, ícone por excelência, segundo Peirce, graças a seu elo físico com a natureza, é presença constante nos filmes de Wim Wenders, pelas quais os personagens pretendem, sem jamais conseguir, obter a prova do real (2006, p. 74).

São as velas que iluminam a romaria noturna e é graças a elas que Dora pode ver as imagens religiosas e fotografias nas paredes da Casa dos Milagres. Desta forma, Salles cria visualmente uma metáfora do dispositivo cinema: uma sala escura em que a luz projetada revela imagens que sensibilizam a retina (e a visão de mundo, em última análise) do espectador. É interessante apontar que o cineasta articula conscientemente esta relação luz- 
cinema-cena romaria e, inclusive, a traz à público em entrevista após a premiação do filme no Festival de Berlim, em 1998. Em suas palavras: "Que mais filmes brasileiros surjam, e que eles sejam, como na romaria de Central, abençoados pela luz que mais alumeia” (BENTES; MATTOS; AVELLAR, 1998, p. 40).

Voltando à análise da cena, temos um plano subjetivo da personagem que está prestes a desmaiar: é uma imagem desfocada simulando efeito de visão turva. Em seguida, seu rosto é tocado por diversas fotos tamanho três por quatro, cujo formato remete à película cinematográfica.

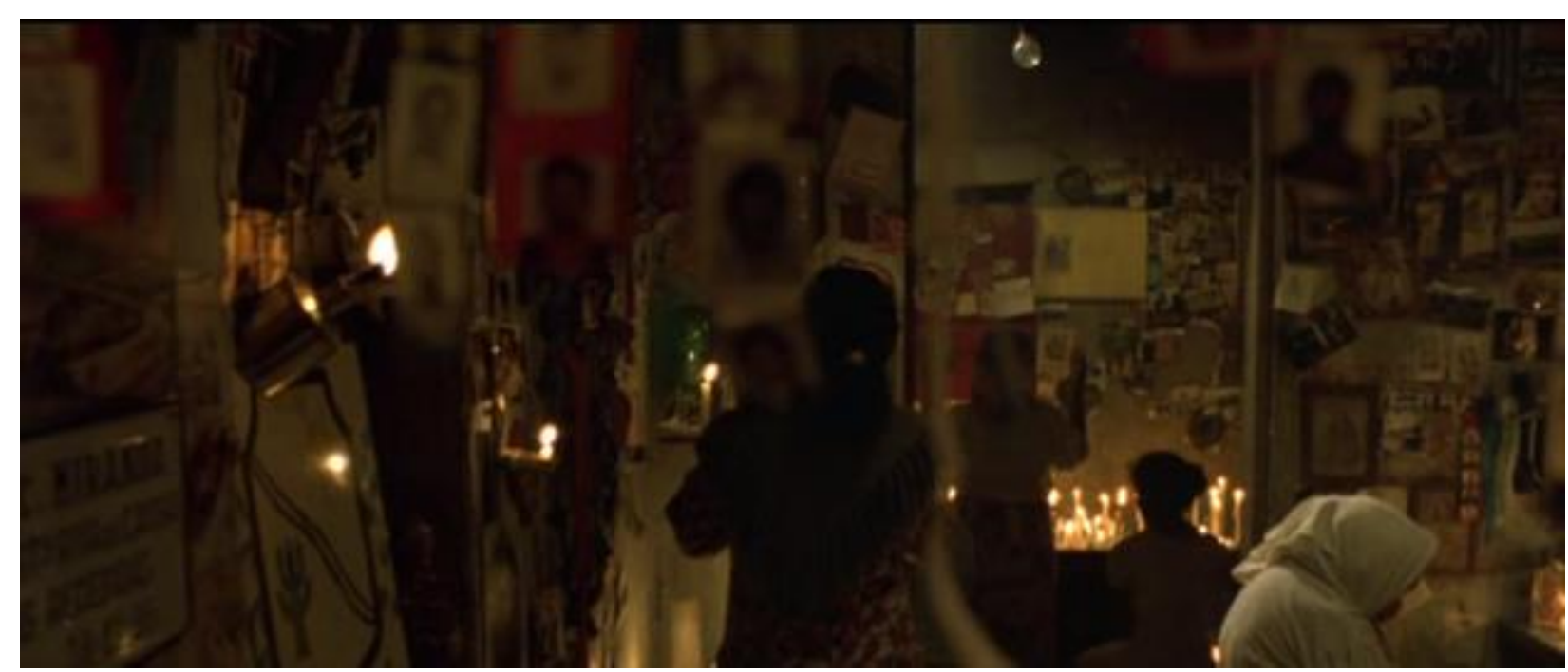

Figura 5 - O plano subjetivo de Dora na Casa dos Milagres contém diversas fotos três por quatro

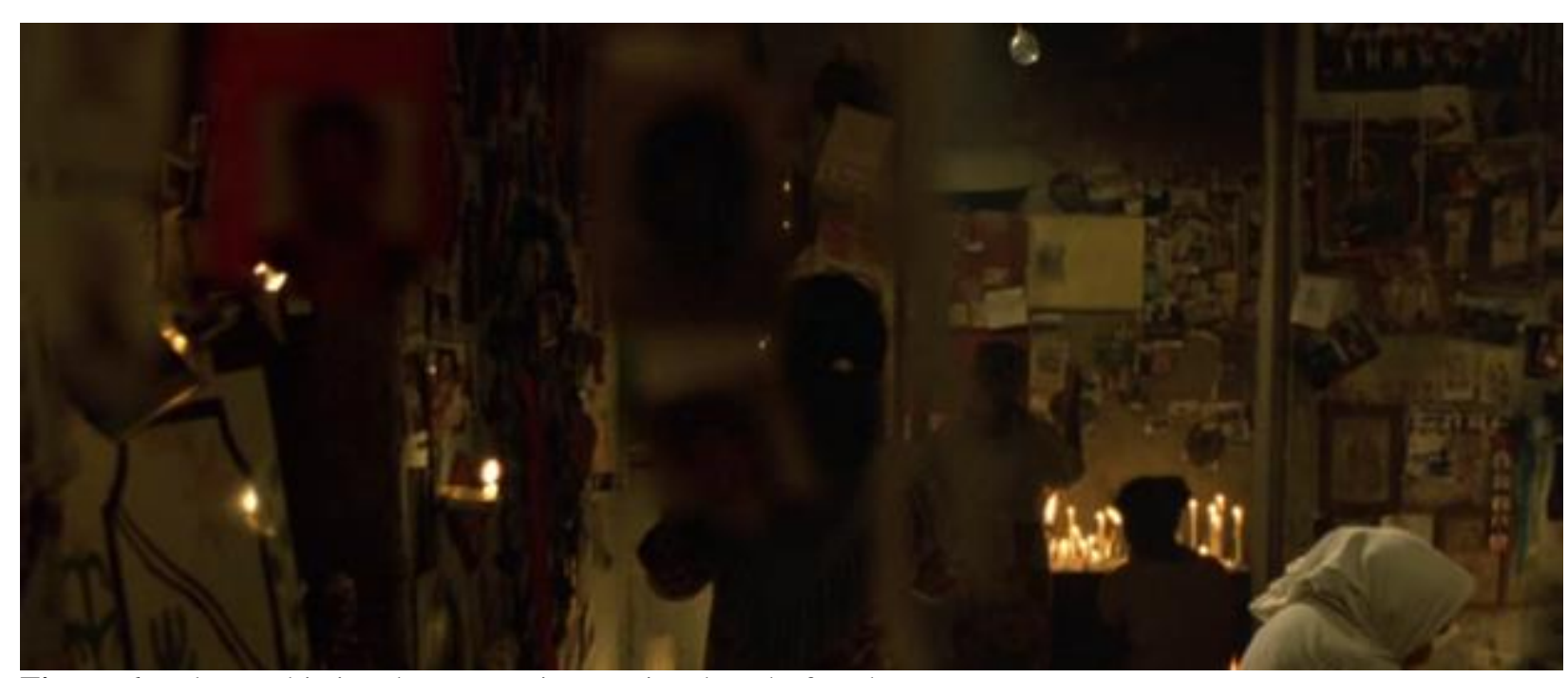

Figura 6 - Plano subjetivo de Dora mais aproximado e desfocado 


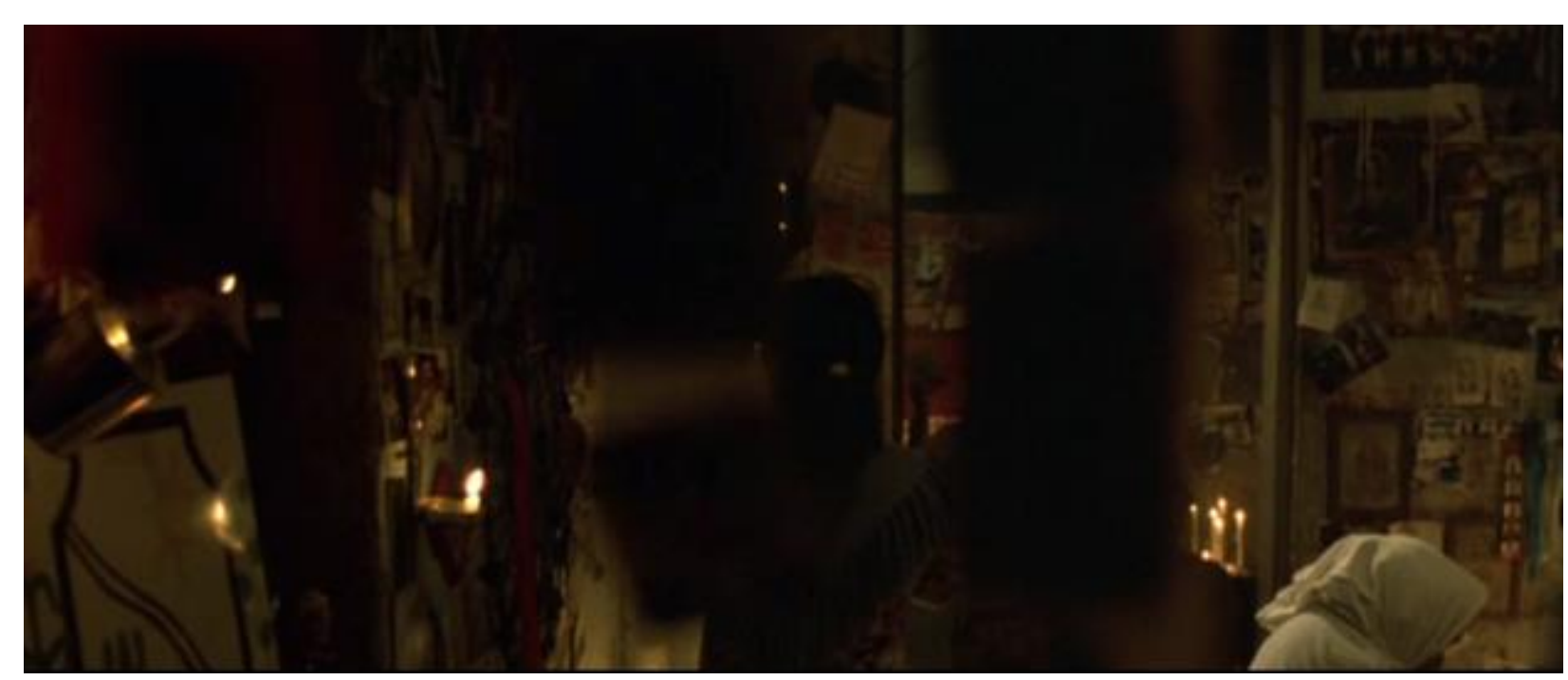

Figura 7 - Plano subjetivo de Dora

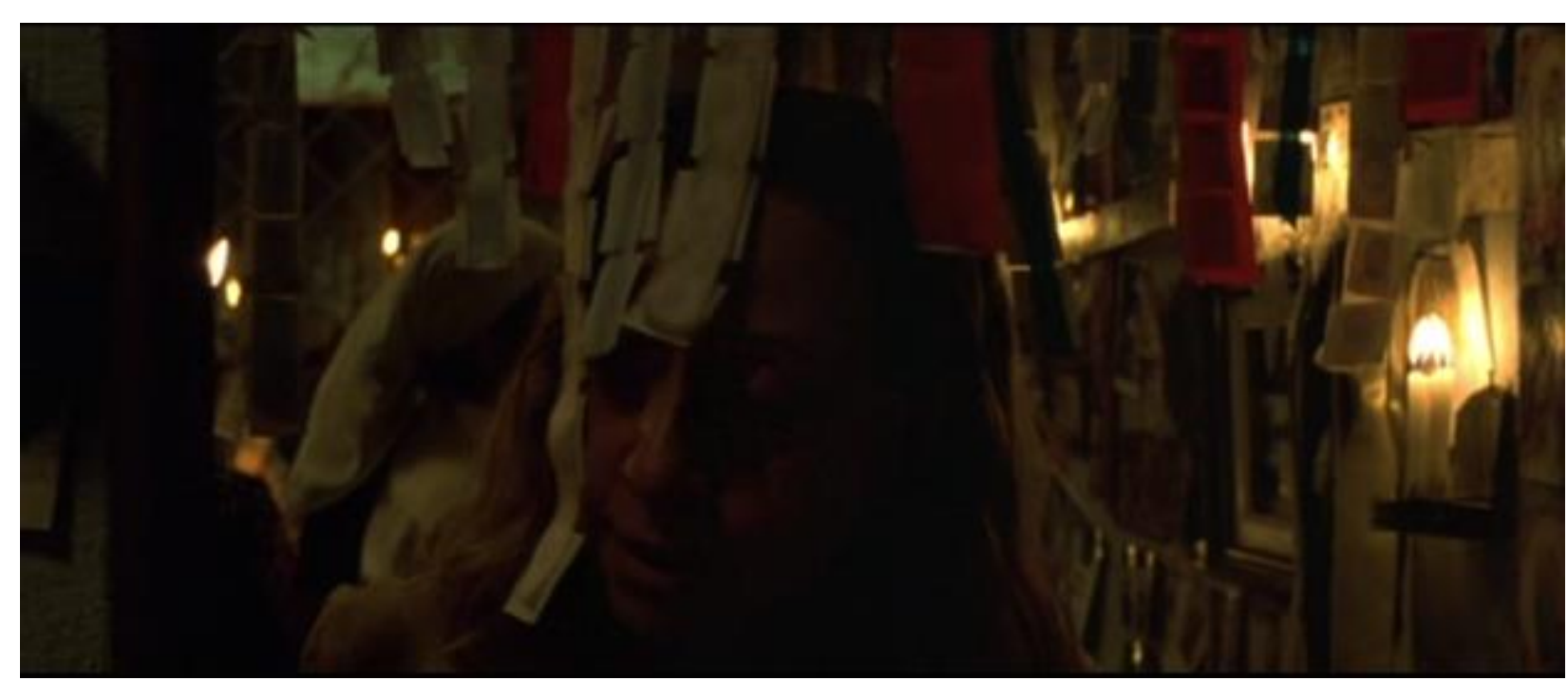

Figura 8 - Contraplano do rosto de Dora sendo tocado pelas fotos três por quatro

Intercalam-se, então, planos de fogos de artifício em que a luz desenvolve trajetória circular, com planos subjetivos da personagem desmaiando, em que a câmera também realiza movimento circular. 


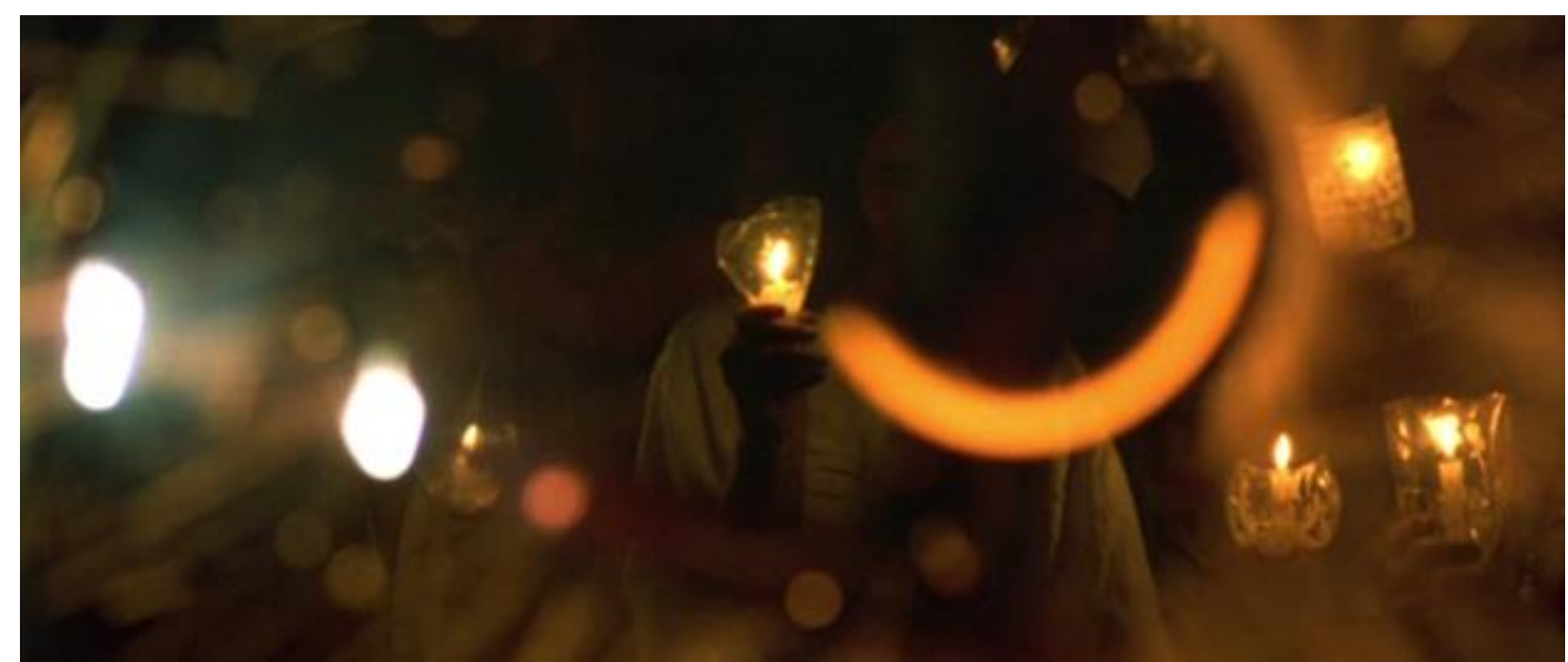

Figura 9 - Plano de fogos de artifício, destaque para a luz desenvolvendo trajetória circular e pontos de luz ao fundo

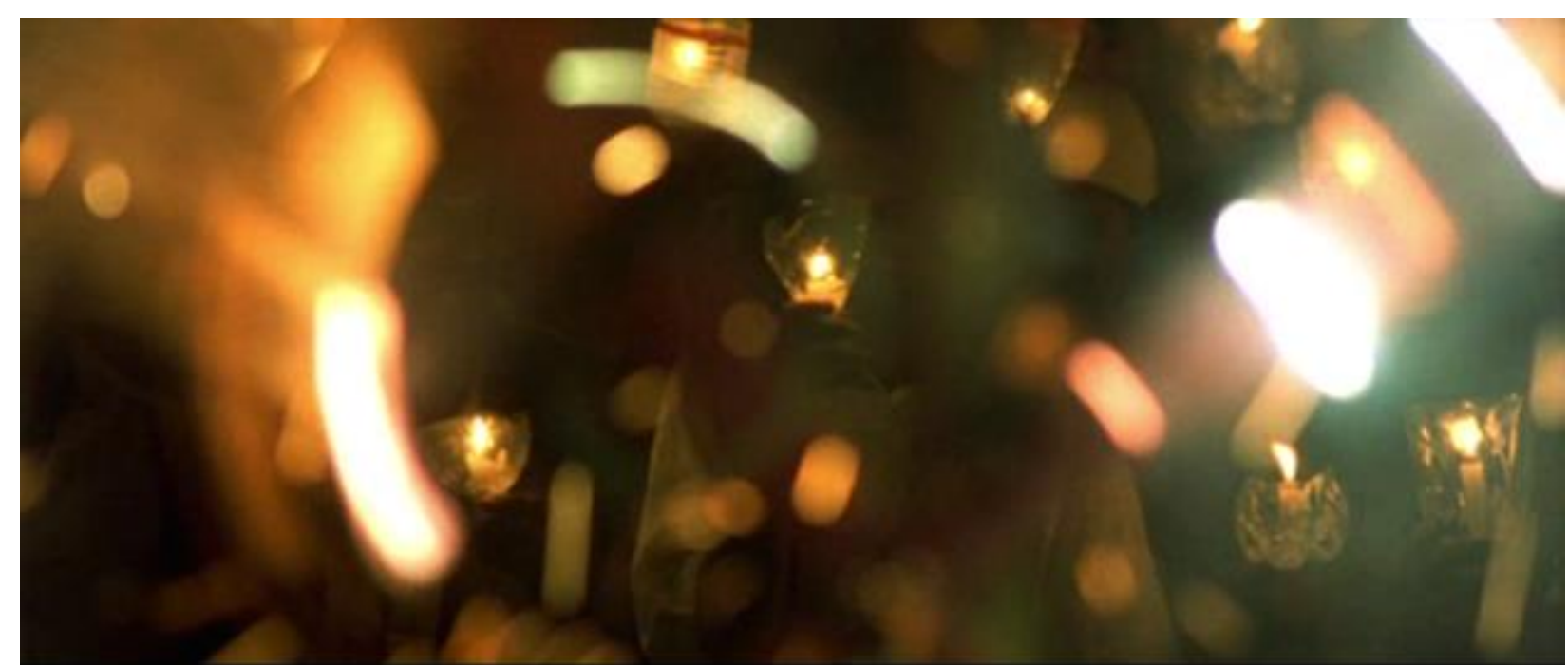

Figura 10 - Plano de fogos de artifício na romaria

Utiliza-se novamente o recurso da montagem paralela para relacionar planos da personagem desmaiada no chão a planos de mais fogos de artifício. A cena termina em um plano aproximado de uma imagem da Virgem Maria com o menino Jesus pendurada em um estandarte, seguida por um fade out. Os frames abaixo ilustram este percurso. 


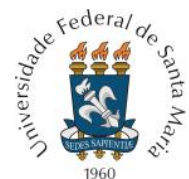

PROGRAMA DE PÓS-GRADUAÇÃO EM COMUNICAÇÃO DA UNIVERSIDADE FEDERAL DE SANTA MARIA

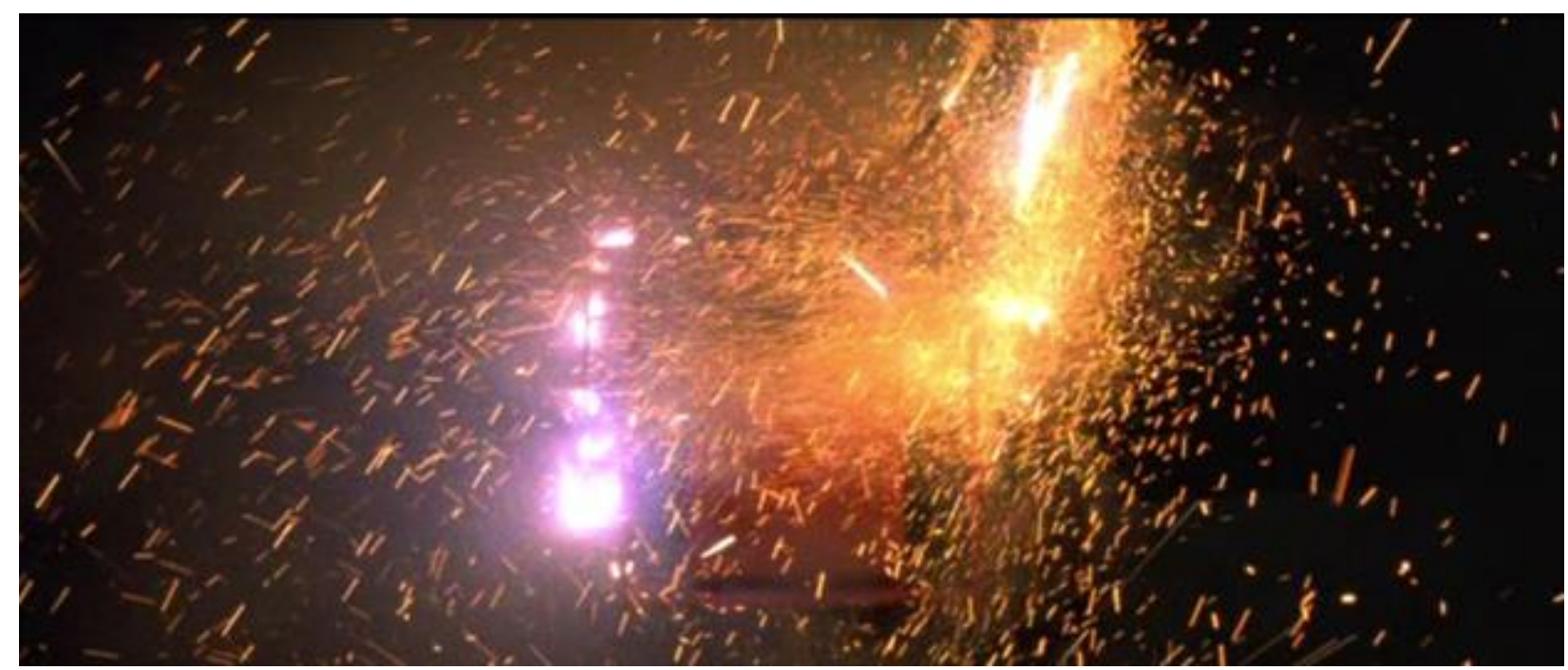

Figura 11 - Plano de fogos de artifício, destaque para a plasticidade da luz

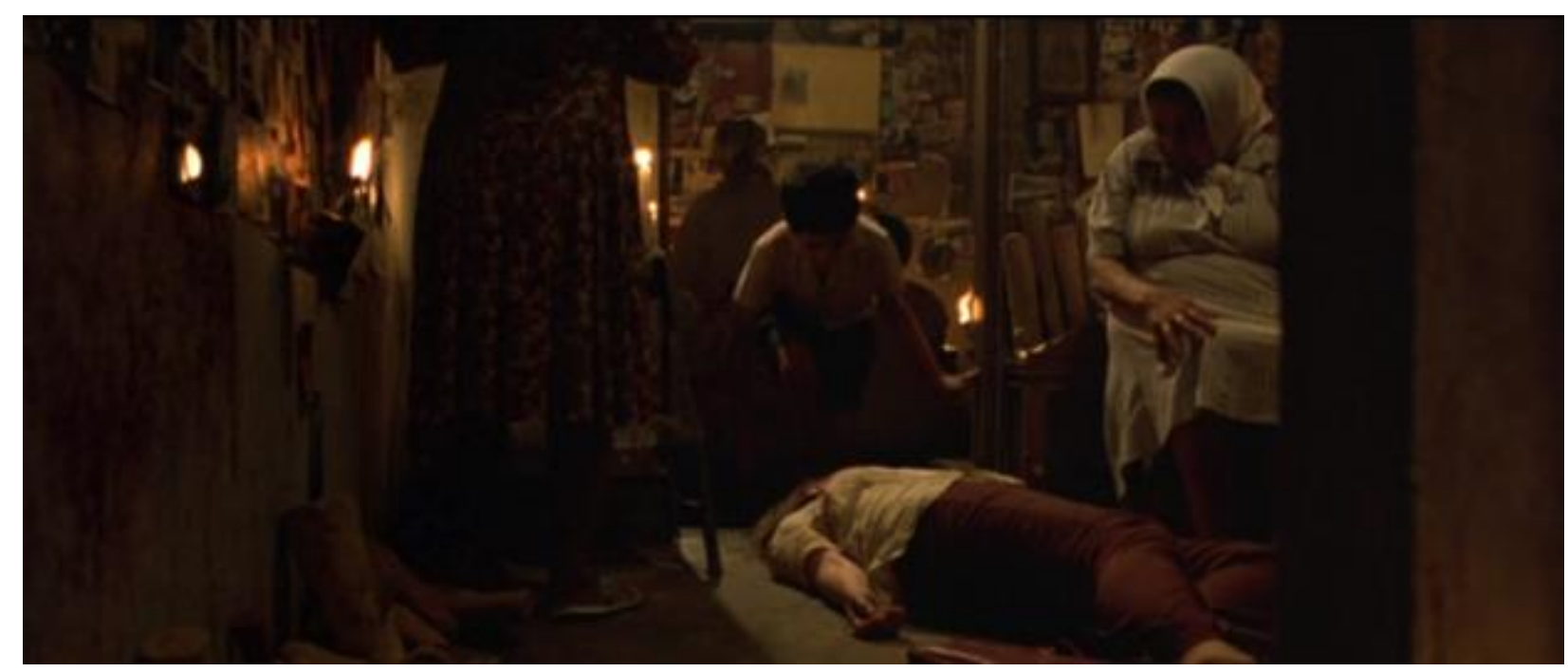

Figura 12 - Plano de Dora desmaiada

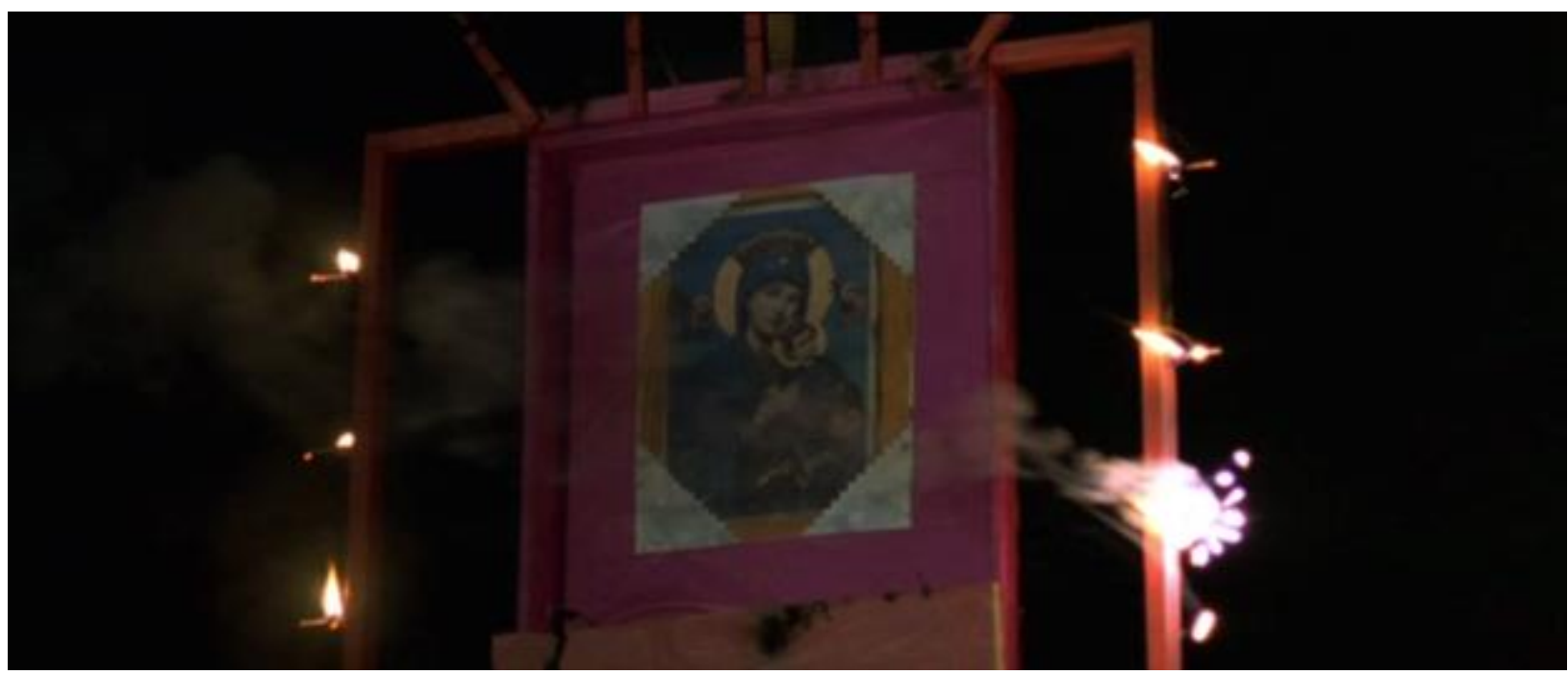

Figura 13 - Plano aproximado de imagem da Virgem Maria com o menino Jesus em estandarte e pontos de luz ao redor 
O plano subjetivo que traz uma imagem desfocada prepara a quebra no registro da imagem-movimento nessa cena. O regime da imagem-tempo é instaurado pelo plano dos fogos de artifício em que a luz desenvolve trajetória circular. Isto acontece pois a imagem do círculo de luz, dotada de grande plasticidade, promove uma pausa na categoria do tempo como um presente abstrato do que é "representado" - objetos, ações, formas de realidade e suas relações sensório-motoras - e funda outra temporalidade, enfatizando o aspecto da imagem como escritura. Neste instante, o efeito de transparência é reduzido drasticamente em detrimento de uma percepção dela como produção do visível, como um efeito de mediação. Portanto, podemos observar nesse plano uma narrativa como acontecimento, já que ele não comunica um acontecimento, mas restitui o efeito vivo da luz e, por decorrência, da experiência cinematográfica, presentifica-os para o espectador.

\section{CONSIDERAÇÕES}

Buscamos demonstrar, por meio da cena da romaria, que o filme Central do Brasil apresenta simultaneamente os dois modos de subjetivação presentes na tipologia deleuziana das imagens cinematográficas: imagem-movimento e imagem-tempo. Além disso, propõe-se que o plano em que predomina a plasticidade da luz em formato circular possa ser lido como aquele que instaura a imagem-tempo na cena. É um dos momentos em que identifica-se a narrativa como acontecimento no filme, de acordo com a concepção de Parente.

Esse plano, visto como um ato de presentificação, introduz uma fissura na representação das ações até então colocadas, promovendo um desdobramento nas imagens. A dobra instaurada pelo acontecimento narrativo abre uma multiplicidade de relações possíveis entre os espectadores e essa imagem fílmica. Uma perspectiva de leitura que apresentamos para essa cena é a metalinguística. Deste ponto de vista, o sentido que se produz é o do cinema como um dispositivo capaz de sensibilizar os espectadores e transformar seus modos de ver o mundo a partir de um pensamento desta arte como revelação.

Além do campo da hermenêutica, a narrativa como acontecimento intensifica a experiência cinematográfica, pois o tempo da imagem e o do espectador se identificam. Desta forma, o tempo é percebido como vivido e cria-se uma relação entre a luz projetada - o princípio do dispositivo cinematográfico - e o espectador. 


\section{REFERÊNCIAS}

BAZIN, André. O cinema: Ensaios. São Paulo: Brasiliense, 1992.

BENJAMIN, Walter. Obras escolhidas - I. Magia e técnica, arte e política. São Paulo: Brasiliense, 1994.

BENTES, Ivana; MATTOS, Carlos Alberto; AVELLAR, José Carlos. "Conversa com Walter Salles - O documental como socorro nobre da ficção". Cinemais, Rio de Janeiro, n. 9, jan./fev. 1998.

NAGIB, Lúcia. A utopia no cinema brasileiro: matrizes, nostalgia, distopias. São Paulo: CosacNaify, 2006.

PARENTE, André. "As virtualidades da narrativa cinematográfica". In: (org.).

Cinema/Deleuze. Campinas: Papirus, 2013, p. 249-270.

STAM, Robert. Introdução à teoria do cinema. Tradução Fernando Mascarello. 4 ed. Campinas: Papirus, 2010.

XAVIER, Ismail. O discurso cinematográfico: a opacidade e a transparência. São Paulo: Paz e Terra, 2005.

\section{REFERÊNCIAS AUDIOVISUAIS}

SALLES, Walter. Central do Brasil. [Filme-vídeo]. Produção de Arthur Cohn e Martine de Clermont-Tonnerre, direção de Walter Salles. Brasil/França, 1998. 113 min. color. son.

WENDERS, Wim. Alice nas Cidades. [Filme-vídeo]. Produção de Joachim von Mengershausen, direção de Wim Wenders. Alemanha, 1974. 110 min. pb. son. 
Doutoranda (bolsista CNPq) do Programa de Pós-Graduação em Comunicação e Semiótica da Pontifícia Universidade Católica de São Paulo, onde desenvolve o estudo Intensidades da imagem: acontecimento narrativo no cinema - análises críticas a partir de Walter Salles. Mestre (2013, bolsista CAPES) em Comunicação e Semiótica pela PUC-SP e bacharel em Jornalismo pela mesma instituição (2008). É uma das autoras do livro Extremidades: Experimentos Críticos, organizado pela Profa. Dra. Christine Mello. Vice-líder do grupo de pesquisa Extremidades: redes audiovisuais, cinema, performance e arte contemporânea do

Programa de Pós-Graduação em Comunicação e Semiótica da PUC-SP. Integrante da plataforma de experimentos críticos lab eXtremidades. Seu campo de pesquisa abrange audiovisual, mais especificamente ficção, documentário, roteiro, cinema brasileiro e cinema contemporâneo. É professora em cursos de Comunicação e Audiovisual no FIAM-FAAM Centro Universitário.

Esta obra está licenciada sob uma Licença Creative Commons. 